\title{
Developing nationwide avalanche terrain maps for Norway
}

\author{
Håvard T. Larsen ${ }^{1,2}$ (D) Jordy Hendrikx ${ }^{2}$ (D) $\cdot$ Martine S. Slåtten $^{1}$ (D) Rune V. Engeset $^{1}$ (D)
}

Received: 24 September 2019 / Accepted: 4 June 2020 / Published online: 12 June 2020

(c) The Author(s) 2020

\begin{abstract}
Snow avalanches are a significant natural hazard in Norway. One method to manage the backcountry avalanche hazard is through detailed mapping of avalanche terrain. Avalanche terrain can be mapped using a variety of methods, including using the Avalanche Terrain Exposure Scale (ATES); however, manual classification of terrain using ATES is time consuming. This study has developed and compared a fully automated algorithm to provide ATES mapping for all of Norway. Our new algorithm is based on the technical model for ATES mapping. This model has specific terrain-based thresholds that can be applied for automated terrain-based modeling. Our algorithm expands on prior work by including the potential release area (PRA) model to identify and calculate the likelihood of an avalanche releasing from a start zone. We also use the raster-based TauDEM-model to determine the avalanche runout length. The final product is a $10-\mathrm{m}$ resolution ATES map. We compared this nationwide ATES map with areas that have been manually mapped by avalanche experts, and find that the automated approach yields similar and reliable results. In addition to comparing mapped areas, we also examine manually mapped linear routes and compare these with the automated mapped ATES areas. Our results suggest that for open terrain, the vast majority of the manually classified tracks are predominantly in the same ATES class as our algorithm. For forested areas, we get mixed results, which can be attributed to a lack of suitable vegetation data at an appropriate scale. Despite this limitation, the current ATES algorithm and resulting spatial data are already valuable as a large portion $(\sim 70 \%)$ of the Norwegian backcountry terrain is above tree line. The automated algorithm is also useful to ensure consistent manual classification across different regions in Norway, or globally, and will permit greater reproducibility and easier updating of mapping for the future.
\end{abstract}

Keywords ATES · GIS · Algorithm · Mapping · Avalanche · Terrain

Håvard T. Larsen

htla@nve.no

1 Norwegian Water Resources and Energy Directorate, Oslo, Norway

2 Snow and Avalanche Lab, Department of Earth Sciences, Montana State University, Bozeman, MT, USA 


\section{Introduction}

\subsection{Background}

A snow avalanche is a mass of snow that slides rapidly down an inclined slope, such as a mountainside. Snow avalanches are triggered by either natural processes (e.g., new precipitation, wind deposition, rapid temperature changes, etc.) or by human activity. Snow avalanches are a significant natural hazard in Norway. On average over the last 20 years, about six people die annually in Norway due to avalanches, with an order of magnitude more in reported close-call accidents. During the winter season 2018-2019, 13 people died due to avalanches (NGI 2019; Varsom 2019a). Furthermore, in every winter, key sections of the Norwegian road and rail networks are closed due to avalanches or avalanche danger. On average, 250 avalanches are registered on Norwegian roads every year (NPRA 2019). Numerous times, vulnerable settlements are completely isolated, forcing long detours due to avalanches blocking key transportation routes, or subject to evacuation by the police.

In Norway, as in several other countries (e.g., Birkeland et al. 2017; Techel et al. 2018), there is a tendency for most of the recent fatal accidents to occur in connection with outdoor activities. In response to this change in avalanche fatalities, there has been a greater emphasis on increased public education and avalanche forecasting, including in Norway (Engeset 2013; Engeset et al. 2018). To supplement the avalanche forecasting and education, efforts have been made to map avalanche terrain (e.g., Statham et al. 2006) and to develop decision aids to guide appropriate terrain use under varying conditions (Haegeli et al. 2006; Landrø et al. 2020).

In many regions around the world, avalanche hazard maps are being generated for different applications. Two distinct types of mapping are (1) hazard zoning maps developed for settlements, roads and industrial sites (e.g., Canadian Avalanche Association 2002; Arnalds et al. 2004; Sauermoser 2006); and (2) hazard maps developed for backcountry recreationalists to be used as a trip planning tool before entering avalanche terrain (e.g., Gruber and Bartelt 2007; Barbolini et al. 2011). The hazard maps developed in this paper are intended for backcountry guidance only and are not legally binding like a municipality risk map for avalanche zoning related to infrastructure. Their purpose is to inform and provide guidance for recreational users, rather than a regulatory framework for planning and enforcement.

In Norway, specifically aimed at outdoor recreationalists, there are two types of ski touring routes that have thus far been manually mapped; observer trips used by the Norwegian Avalanche Warning Service (NAWS) (Landrø et al. 2016), and trips described in some of the recent ski touring guidebooks. However, such routes are generally not available nationwide for backcountry terrain due to the level of manual work required to generate them.

To delineate avalanche hazard maps at national scales, automated models must be used (Bühler et al. 2018). Different types of backcountry hazard maps exist, they can be broadly divided into two types; (1) outlining degree of hazard, often low, moderate, high (e.g., Statham et al. 2006; Barbolini et al. 2011; Harvey et al. 2018), or (2) continuous which contains dynamic hazard values ranging from 0 to 1 where increasing value indicates increased hazard (e.g., Schmudlach and Köhler 2016; Harvey et al. 2018).

One approach that is of particular relevance and fits within this first category is the Avalanche Terrain Exposure Scale (ATES). ATES is a terrain classification system 
developed by Parks Canada to better communicate the complexities and risks of traveling in avalanche prone terrain (Statham et al. 2006). Campbell and Gould (2013) refined this approach and proposed a practical model for semi-automated classification of avalanche terrain.

In 2014, the Norwegian Water Resources and Energy Directorate (NVE) published a pilot study in collaboration with Grant Statham from Parks Canada to determine whether the Canadian ATES classification could be adapted for use in Norway. A Norwegian version was evaluated and a few locations across the country were manually classified by experts at the Norwegian Avalanche Warning Service (NVE 2014). Furthermore, during the winter season of 2018-2019, 123 popular routes used for ski-touring were manually classified by NVE using the modified ATES classification scheme (Varsom 2019b) in three test regions; Troms, Lofoten and Romsdalen in Norway. A total of $586 \mathrm{~km}$ of classified tracks are now available online to the public (Varsom 2019c).

\subsection{Objectives}

The objective of this paper is to expand on the manual ATES mapping and manual route classification in Norway, and develop an automatic algorithm for high spatial resolution ATES mapping for all of mainland Norway. The resulting map was then compared to areas and linear features (popular ski tours) mapped by avalanche experts using a manual approach.

Our specific aim is to present the automated mapping methods, compare them to expert generated maps and demonstrate how this new approach can provide quantitative assessment of manually assessed areas and routes, to increase consistent and reproducible ATES classification across different regions in Norway, or globally.

\subsection{Study area}

This study covers the mainland of Norway including islands in close proximity to the coastline. In total, $365,246 \mathrm{~km}^{2}$ of terrain is mapped stretching from $58^{\circ} \mathrm{N}$ to $71^{\circ} \mathrm{N}$ and $5^{\circ}$ $\mathrm{E}$ to $31^{\circ} \mathrm{E}$ (Fig. 1). The land surface is ranging from sea level to $2469 \mathrm{~m}$ a.s.l. and there is snow on the ground for a minimum of 3-8 months as a function of latitude and elevation. The landscape has a large variation of terrain and vegetation types due to its large range in latitude and longitude, as well as distance from the sea.

The NAWS produces daily avalanche forecasts for mainland Norway for 21 A-rated regions (Fig. 1) and 21 B-rated regions. Daily avalanche forecasts are published every day for all A-rated regions from 1st of December until 31st of May, and these forecasts are based on regular manual field observations of snow and avalanches using Regobs (Engeset et al. 2018). Avalanche forecasts are published for B-rated regions, if the weather forecast indicates the likelihood of an avalanche danger rating of high (4) or very high/extreme (5).

In northern Norway in Troms County, three popular ski touring mountains were manually mapped by avalanche experts using zonal ATES, collectively covering $25.3 \mathrm{~km}^{2}$. These areas are Fagerfjellet, Gabrielfjellet and Skittentinden (Fig. 1). Furthermore, three popular ski-touring regions have been mapped in Troms (41 routes, $191 \mathrm{~km}$ ), together with Lofoten (30 routes, $113 \mathrm{~km}$ ) and Romsdalen $(52$ routes, $281 \mathrm{~km}$ ). All in all 123 routes with a summarized route length of $586 \mathrm{~km}$ are analyzed. A portion of each region, with examples of the ATES regional mapping and mapped linear features, is shown in Fig. 1. The regions are characterized by a mountain fjord landscape with steep mountains and u-shaped valleys 


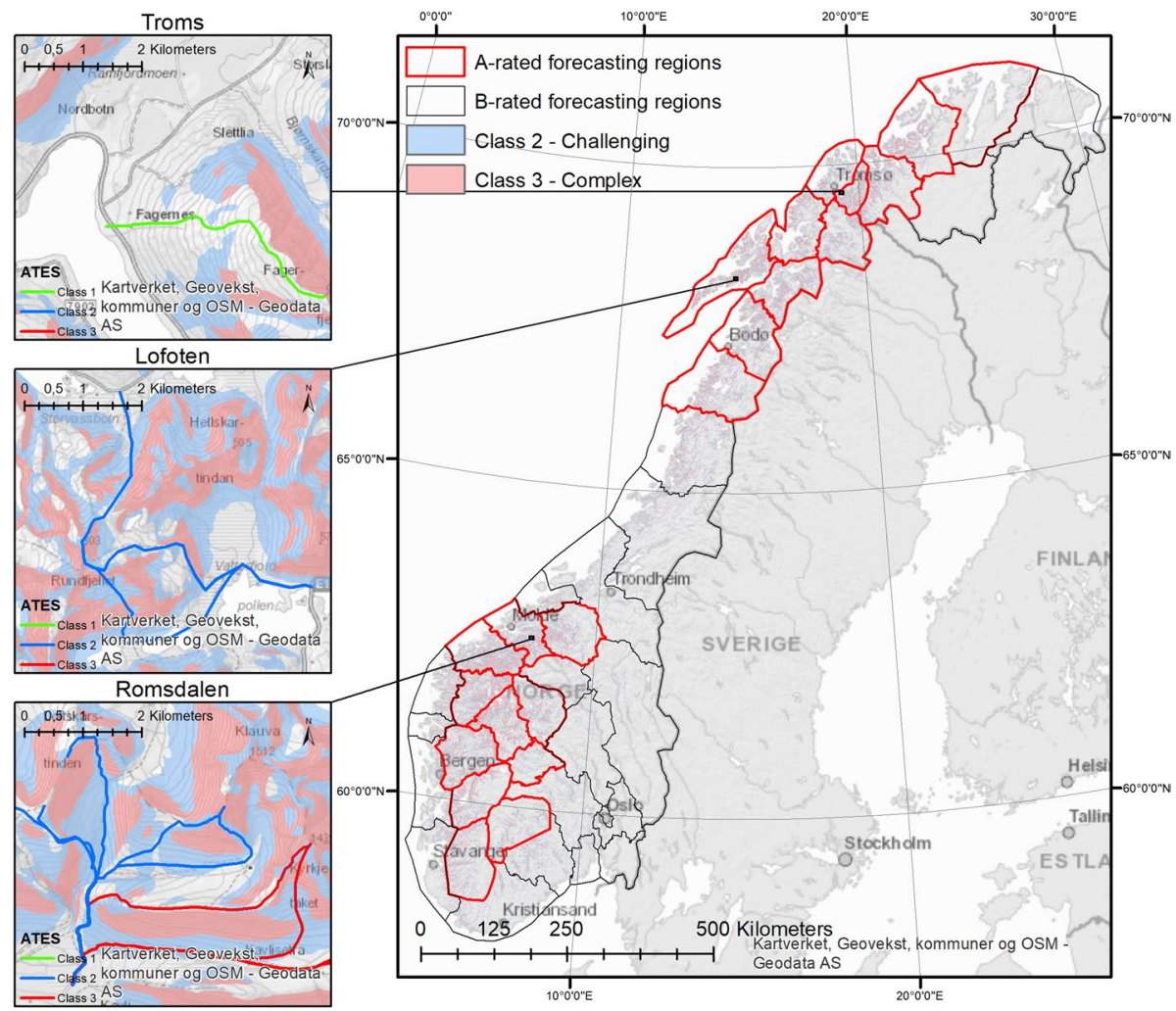

Fig. 1 ATES v.1.04 mapped for all of Norway where Challenging and Complex terrain is colored in blue and red, respectively. The Norwegian Avalanche Warning Service (NAWS) A- and B-rated forecasting regions are shown on the map (right). A portion of each case study region for Troms, Lofoten and Romsdalen are shown from the top, on the left

as a result of glacial erosion. The mountains rise from sea level to $1000-1500 \mathrm{~m}$ a.s.l. The elevation of the tree line decreases with latitude, from approximately $800 \mathrm{~m}$ a.s.l. in Romsdalen in the South to approximately $300 \mathrm{~m}$ a.s.l. in Troms in the North.

\subsection{ATES}

The ATES model was designed to easily communicate the avalanche terrain complexities and risks to novices. To do so, the model is divided into two separate components, a public communication model and a technical model. The technical model is used to guide experts using 11 parameters to categorize a route into a public communication model consisting of three classes; Class 1 "Simple", Class 2 "Challenging", or Class 3 "Complex" (Statham et al. 2006). The public model is only a text-based classification of a linear route. However, Statham et al. (2006) suggest that a future goal would be to apply this model spatially. Delparte (2008) made the first attempt to apply this model spatially, and identified slope angle and forest density as the most important factors. During the period 2009-2012, $4000 \mathrm{~km}^{2}$ of avalanche terrain was mapped spatially using the qualitative method designed for linear routes. Campbell et al. (2012) 
identified problems in this method and stated the need for a more quantifiable model, as well as the need for a non-avalanche terrain class. Having identified slope angle and forest density as the most important factors, $2000 \mathrm{~km}^{2}$ of manually mapped terrain in British Colombia Canada was analyzed so that empirical thresholds could be quantified. As a result of this study, a set of terrain and vegetation thresholds (Table 1) were proposed as a model for mapping with the ATES model (Campbell and Gould 2013).

In Canada, as of 2013 over $8000 \mathrm{~km}^{2}$ of terrain has been ATES mapped at the basin scale of $100 \mathrm{~m}$ to $1 \mathrm{~km}$ (Campbell and Gould 2013). This approach is useful for recreational trip planning or industrial planning operations, but not for detailed route finding in complex terrain, where a spatial scale of $20-30 \mathrm{~m}$ is needed. Larger scale (i.e., higher resolution) maps are therefore needed for more detailed route decision-making (Schweizer 2003; Thumlert and Haegeli 2017). To address this deficiency, several different approaches have been utilized so far. Using a 30-m DEM, Gavaldà et al. (2013) and NVE (2014) spatial mapped areas in Spain and Norway using a manual approach from the qualitative and linear ATES v1.04 model (Statham et al. 2006). In contrast, using observed terrain use of professional ski guides, Thumlert and Haegeli (2017) showed that it is possible to derive ATES empirically at a 20-m scale. Finally, Schmudlach and Köhler (2016) proposed a new method for an automated ATES classification at a 10-m scale; however, this model is not validated. They suggested that for the spatial ATES classification to become widely implemented, a fully automated algorithm would need to be developed.

\section{Methods and data}

\subsection{Development of an automated ATES algorithm}

\subsubsection{Digital terrain model}

A digital terrain model (DTM) for Norway was downloaded from the Norwegian Mapping Authority in the nationwide $10 \times 10 \mathrm{~m}$ raster model (Kartverket 2013). The coordinate system EUREF89 Universal Transverse Mercator Zone 33, 2d+NN54, one of Norway's official coordinate systems, was used. The vertical standard deviation of the DTM used is \pm 4 to $6 \mathrm{~m}$ and the scale is 1:10,000 (Kartverket 2013).

\subsubsection{Slope}

A slope raster was delineated according to the thresholds for open terrain proposed by Campbell and Gould (2013) in ESRI ArcMap 10.6. All slope angles above $40^{\circ}$ were assigned class 3 (complex); values between $40^{\circ}$ and $25^{\circ}$ were assigned class 2 (challenging). Slope inclines below $25^{\circ}$ were assigned class 1 (simple) and the optional class 0 (non-avalanche terrain) threshold was applied at $15^{\circ}$. Areas with slope angles below $15^{\circ}$ could still be assigned a higher terrain class if the subsequent steps in the analysis showed this terrain to be in the runout of an avalanche path. The delineated classes were then exported as a shapefile for each class (Fig. 3). 


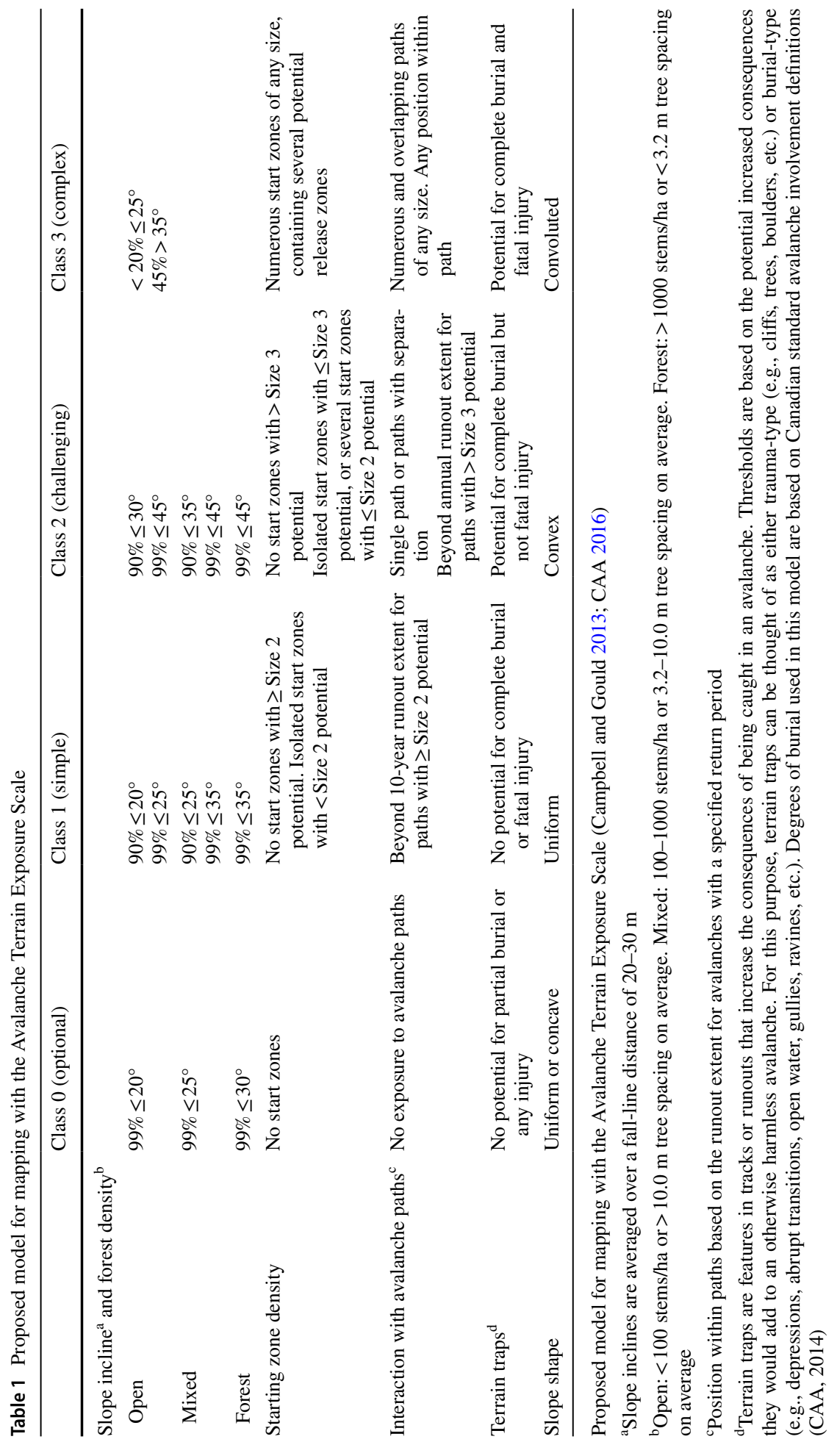




\subsubsection{Potential release area}

To calculate the avalanche path start zone density (Table 1), the potential release area (PRA) algorithm is used (Veitinger and Sovilla 2016a, b). The algorithm uses three criteria; slope, wind shelter index and roughness, as calculated from the input parameters; a DTM, average snow depth, and main wind direction (optional, but not used in this analysis) (Fig. 2). Using a 10-m DTM, the roughness criteria are neglected due to the coarse scale, as the script is optimized for a 2-m DTM (Veitinger and Sovilla 2016b). The PRA algorithm is written in the programming language $\mathrm{R}$ ( $\mathrm{R}$ Core Team 2017). Important functions are accessed by the RSAGA package (Brenning 2008), connecting to the open-source SAGA GIS software (Conrad et al. 2015). The PRA output is an ASCII raster file assigning values between 0 and 1 for each cell, with higher values suggesting an increased likelihood of avalanches to release. In this paper, values below 0.05 are not considered to be a starting zone. The values between 0.05 and 1 were exported as a shapefile and assigned class 3 (Fig. 3).

Slope angles between 28 and $60^{\circ}$ are considered to be possible release areas. Therein slope angles between $35^{\circ}$ and $45^{\circ}$ are assigned the largest membership value. On each side, the membership values decrease and slope angles below $30^{\circ}$ and above $50^{\circ}$ are assigned low membership values.

The wind shelter index, which is also a PRA calculation, is used instead of a curvature measure. Wind-exposed terrain have negative values and are assigned low membership values, wind-sheltered terrain have positive values and are assigned high membership values.

The roughness factor is derived from the neighboring tiles in the raster in a $3 \times 3$ window. Given that we are using a $10 \mathrm{~m}$ DTM, the scale of the roughness factor is therefore averaged over a line of $30 \mathrm{~m}$. Planar and smooth terrain are assigned low roughness values and high membership values because these are more prone to avalanche. Rough surfaces are assigned high roughness values and are less likely to avalanche (Veitinger and Sovilla 2016a, b).

\subsubsection{Avalanche runout}

To estimate the potential avalanche runout, the hydrologic terrain analysis software TauDEM and TauDEM toolbox for ESRI ArcMap (Tarboton 2005) were used to derive interaction with avalanche paths identified from the DTM (Table 1). TauDEM is a suite of tools that can compute the avalanche runout length when a specified alpha angle is

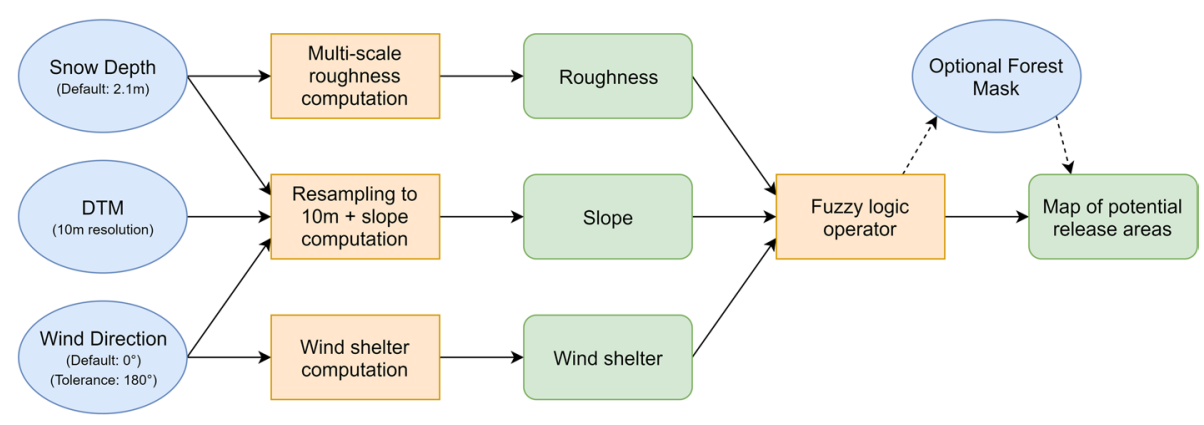

Fig. 2 Flowchart of the PRA algorithm (modified from Veitinger et al. 2016) 


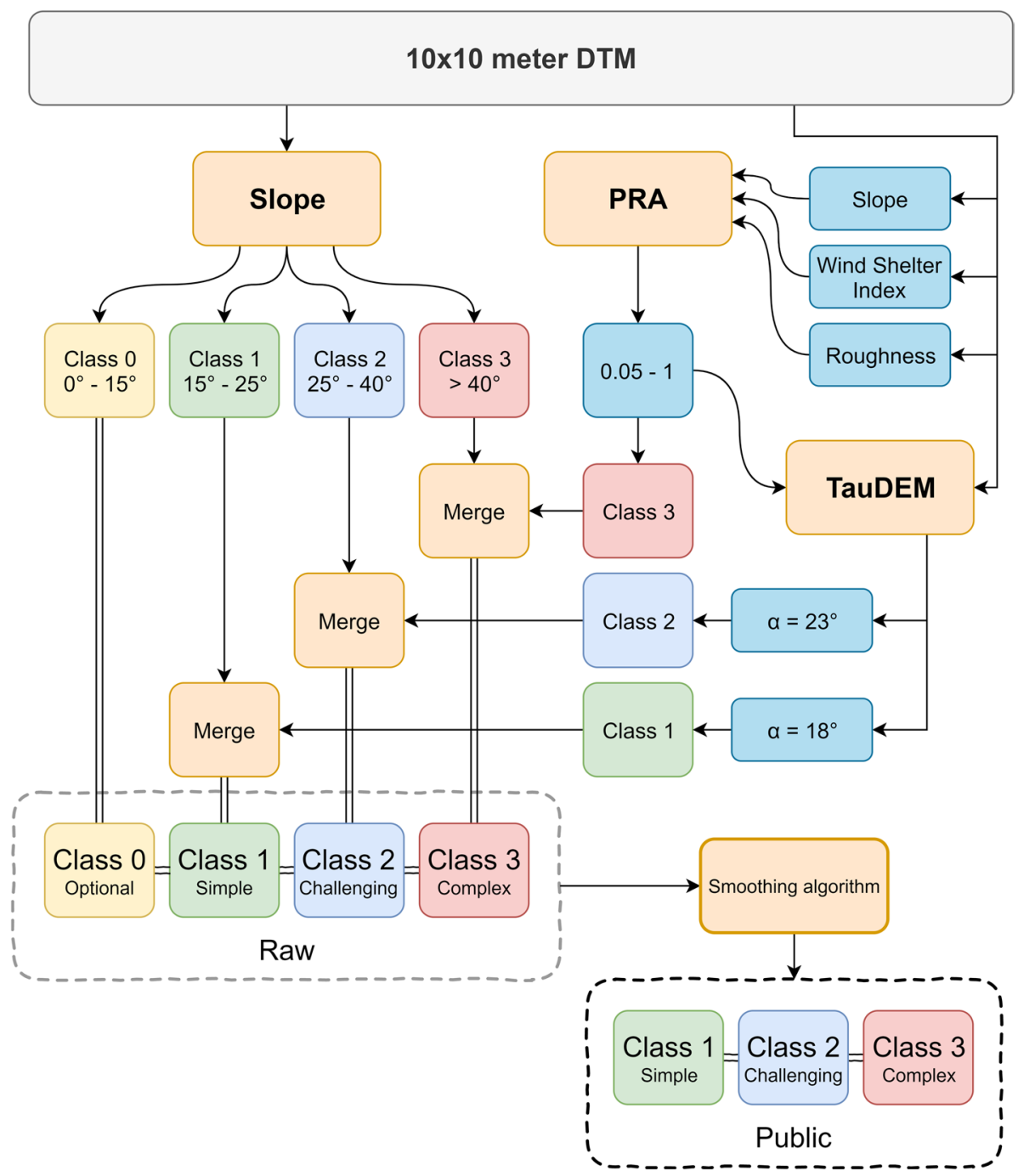

Fig. 3 Flowchart showing all processing steps of the automated ATES algorithm (v.1.0)

provided. The D-Infinity Avalanche is a function tool in TauDEM, which may be used to detect all locations downslope of a given starting cell(s) until a given alpha angle from the starting cell is reached (Tarboton 2013). In the algorithm, avalanche runouts were calculated for using the tools from TauDEM and chosen alpha angles. These runout alpha angles were based on studies of return periods of avalanche runouts in Norway (Lied and Bakkehøi 1980).

The advantage of using the alpha angle to estimate the runout length is that it is a powerful input variable to fine tune the algorithm runout estimations for different regions and climates. Lied and Bakkehøi (1980) undertook empirical studies on 423 well-known maximum extents of avalanche events in Norway. They found that $100 \%$ of 
avalanches stop within an alpha angle of $18^{\circ}$ and $95 \%$ stop within $23^{\circ}$. Due to this, all runouts within an $18^{\circ}$ alpha angle would be classified as simple terrain. Avalanches do not normally run that far downslope, so a $23^{\circ}$ runout angle was set as the threshold for challenging terrain, having more frequent avalanches.

\subsubsection{Large-scale ATES mapping}

ATES mapping was first conducted for three small areas; Fagerfjellet, Gabrielfjellet and Skittentinden (approx. $25 \mathrm{~km}^{2}$ ) in Troms county. These three areas were selected to permit direct comparison to the manual, expert-guided ATES mapping that had already been completed (NVE 2014). However, to go from the mesoscale (mountain) to macroscale (whole of Norway), the entire process had to be automated for efficient processing. All steps were automated in a script using Python 2.7 (Larsen 2019a, Fig. 3). To increase the efficiency of processing, the entire study area of Norway had to be divided into several smaller tiles. To eliminate the potential of having avalanche runouts stop along the borders of these tiles before they were modeled to their full runout potential, all tiles were created using watershed boundaries. With the available processing power, it was found that smaller tiles $\left(<4000 \mathrm{~km}^{2}\right)$ were possible to process (using a desktop computer with 32 GB RAM, HDD and $3.6 \mathrm{GHz}$ Intel Core i7 processor). The study area was divided into 395 watershed tiles with a given feature identification (FID) number, tiles were then processed one at a time following the list of FID numbers in a.bat file. The advantage of using this method is that if the processing of one tile was incomplete, the computer skipped to the next tile and the incomplete tile could be reprocessed at a later stage. The processing time for the entire mainland Norway was approximately $500 \mathrm{~h}$.

\subsubsection{Merging and generalization}

The resulting "raw" output from the automated ATES algorithm is at very high spatial resolution compared to the previously mapped areas with ATES and includes some noise as a result of smaller terrain features. With the current DTM accuracy with a standard deviation error of up to 4-6 m, these resulting maps could be interpreted at a higher resolution than intended. To address this issue of the perception of increased accuracy due to this greater precision from the DTM, the resulting layers needed to be smoothed, such that smaller areas are combined into the adjacent ATES classes to produce a more generalized "public" version of the ATES mapping.

In the public available maps from Varsom (2019c), we use a smoothing factor of $500 \mathrm{~m}$ using the PAEK algorithm (Bodansky et al. 2002) as well as removing all polygons smaller than $25,000 \mathrm{~m}^{2}$, assigning them the surrounding class value (Larsen 2019b). This final dataset which is exposed to the public is equivalent to the finer scale resolution that Avalanche Canada use in their manual ATES maps, which are presented at a 100-1000 m scale (Campbell and Gould 2013). However, the current version of the algorithm (v1.0, 2020), which is available to the public online has a scale lock set at 1:100,000, where further zooming in on this layer results in the layer disappearing from view. 

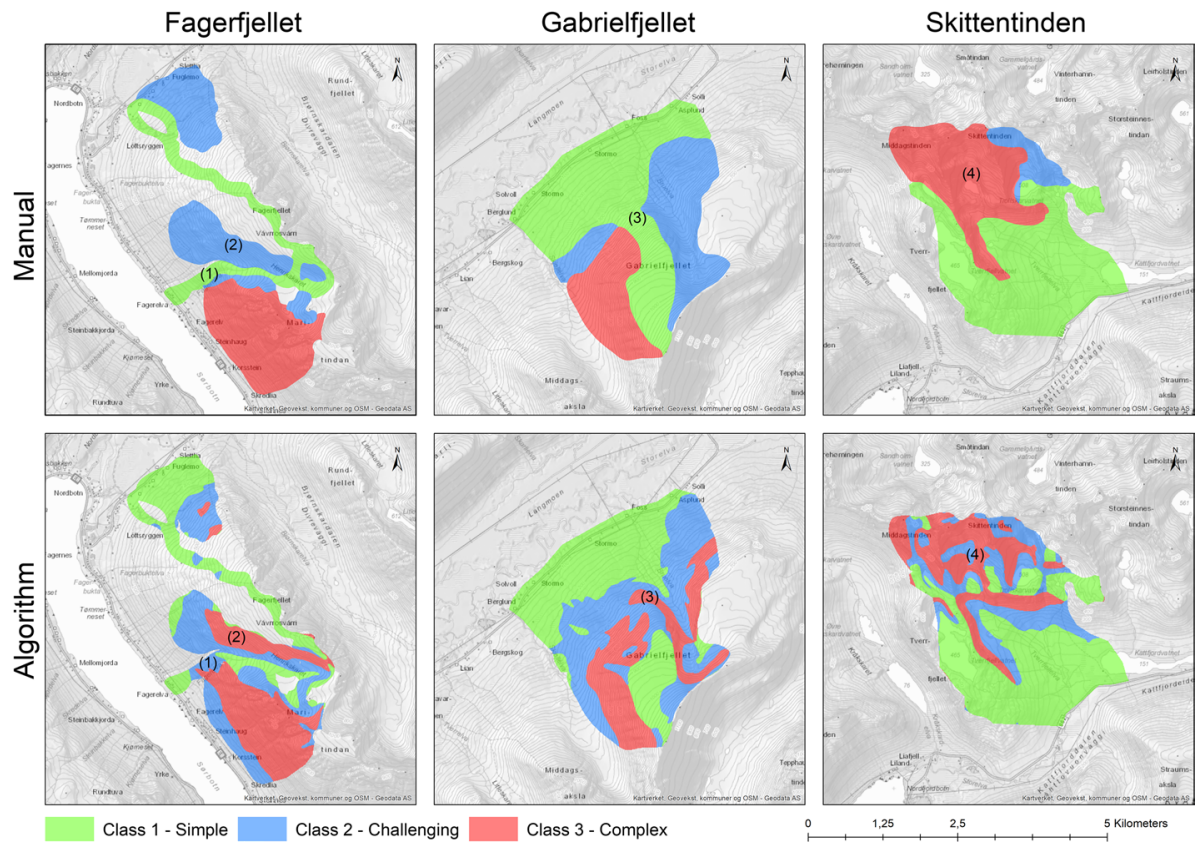

Fig. 4 The three case study areas Fagerfjellet, Skittentinden and Gabrielfjellet used to evaluate the ATES algorithm's performance (v.1.0). The upper three maps are from the NVE (2014) manual mapping, while the lower three maps are the output from the automated algorithm explained in this paper. The numbers in the figure are reference points mentioned in the discussion

\subsection{Methods for model validation and comparison}

\subsubsection{Spatial validation}

To assess how robust the automated ATES algorithm is, we compare it with manual ATES classification published by NVE in 2014 from the three mountains in Norway; Fagerfellet, Skittentinden and Gabrielfjellet (Fig. 4). The spatial extent of the manual ATES classification maps is used to clip out a relevant area from the automatic ATES map, such that these rasters are equal in area and extent. Then, for each class in the manual ATES classification, the percentage agreement with each class in the automatic ATES map is plotted in a bar plot. This is then repeated for each class at each site, resulting in a total of 9 bar plots (Fig. 5).

\subsubsection{Linear validation}

Manual classification of ATES tracks is less complex and time consuming to map for an avalanche expert compared to spatial maps; therefore, a lot more data are available for comparison to the automatic ATES maps. Before the 2018/2019 season, NVE recruited one avalanche expert with local knowledge from each area of interest to map the mountains in their region using the ATES classification scheme. A GIS web tool in the browser 

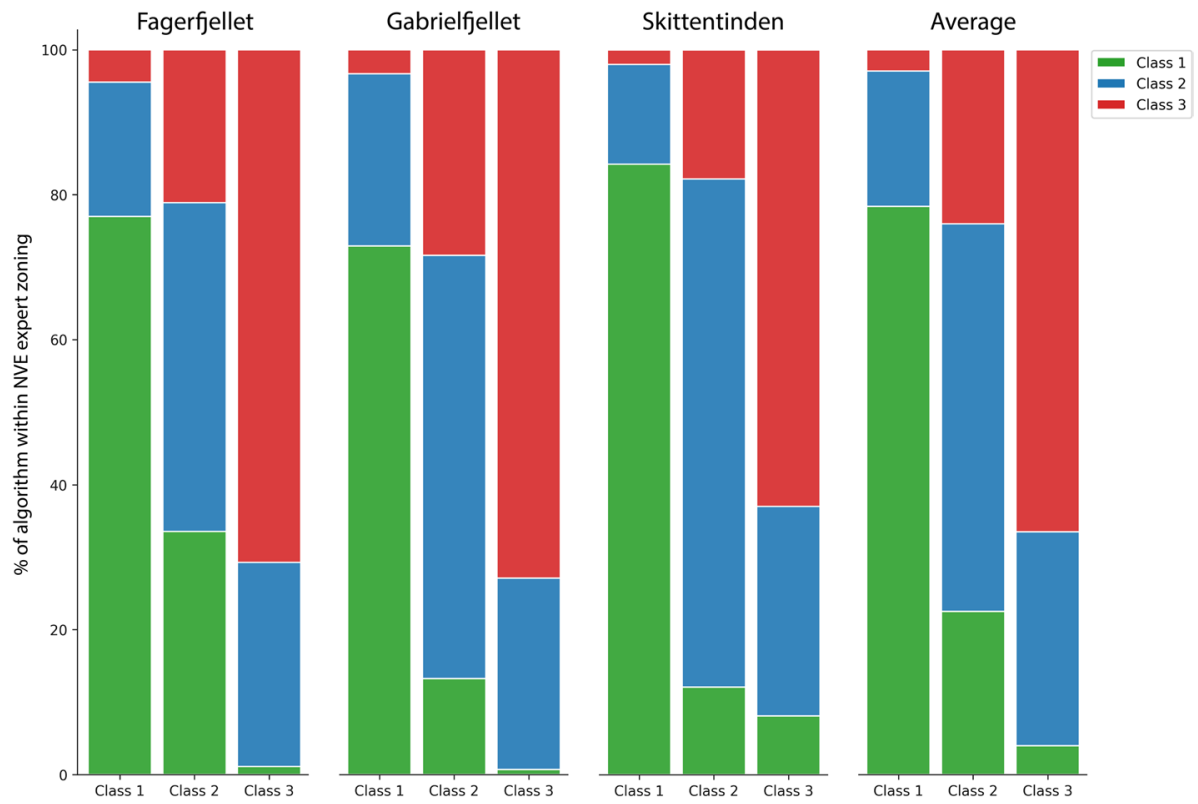

Fig. 5 Visual illustration of the percentage agreement score presented in Table 2

was created, making it easy for the experts to draw and classify each route. In the end of the project, they reviewed each other's work. In total, NVE classified $586 \mathrm{~km}$ of tracks from 123 different routes in the Troms, Lofoten and Romsdalen regions (regions are shown in Fig. 1). The Norwegian ATES classification differs slightly from the original version emphasizing cornices more and includes a class 0 (non-avalanche) terrain (Varsom 2019b). To compare these results against the spatial automated ATES maps, all manually classified tracks were sorted by their region and class value. Then, the tracks were split into points every $10 \mathrm{~m}$. For each point, the corresponding value from the automated ATES map raster was extracted, and the resulting data were compared against each other. The results are presented in a table showing the percent agreement score for each class.

\section{Results}

In total, $365,246 \mathrm{~km}^{2}$ of terrain was ATES mapped in Norway using our automated algorithm. This represents $100 \%$ of the total land area of mainland Norway including all of the 22 forecasting regions. Of this total area, $71 \%$ was non-avalanche terrain (class 0), 13\% was simple terrain (class 1), 9\% was challenging terrain (class 2), and $7 \%$ was complex (class 3). Since April 2019, the data are publicly available via a map-based online tool for trip planning on this webpage (Varsom 2019c).

\subsection{Algorithm spatial performance}

To assess the spatial properties of the new automated ATES algorithm, we compared the results to expert-guided maps classified by NVE (2014) for three areas in Troms county 
Table 2 Percentage agreement score for each case study location comparing the manual NVE classification and the automated ATES algorithm

\begin{tabular}{lccc}
\hline & \multicolumn{2}{l}{ Automated ATES $(\%)$} & \\
\cline { 2 - 4 } & Class 1 & Class 2 & \\
\hline NVE expert spatial & & & \\
Fagerfjellet & & & 4.45 \\
Class 1 & $\mathbf{7 7 . 0 1}$ & 18.54 & 21.12 \\
Class 2 & 33.55 & $\mathbf{4 5 . 3 3}$ & $\mathbf{7 0 . 7 2}$ \\
Class 3 & 1.11 & 28.17 & \\
Gabrielfjellet & & & 3.32 \\
Class 1 & $\mathbf{7 2 . 9 0}$ & 23.78 & 28.37 \\
Class 2 & 13.25 & $\mathbf{5 8 . 3 9}$ & $\mathbf{8 8 . 8 3}$ \\
Class 3 & 0.82 & 32.35 & \\
Skittentinden & & & 2.01 \\
Class 1 & $\mathbf{8 4 . 2 2}$ & 13.77 & 17.82 \\
Class 2 & 12.10 & $\mathbf{7 0 . 0 9}$ & $\mathbf{6 2 . 9 8}$ \\
Class 3 & 8.10 & 28.92 & 2.92 \\
Average & & & $\mathbf{6 6 . 4 9}$ \\
Class 1 & $\mathbf{7 8 . 3 8}$ & 18.72 & \\
Class 2 & 22.51 & $\mathbf{5 3 . 4 5}$ & 29.51 \\
Class 3 & 4.00 & & \\
\hline
\end{tabular}

Bold values represent the percentage agreement values where both the automated and manual systems provided the same ATES class

(Fagerfjellet, Skittentinden and Gabrielfjellet). A visual comparison of the manual maps vs. the automated algorithm is shown in Fig. 4 and the result of the comparison in Fig. 5.

The manual expert classification was undertaken by NVE in 2014 also considered forest density, terrain traps and interaction with avalanche paths, something which the current version of our automated ATES algorithm does not. Future work will address this deficiency once forest density layers at the appropriate scale are available. As such, areas below 300-350 $\mathrm{m}$ a.s.l. may be incorrectly classified in some locations as a result of the lack of forest cover consideration in the automated ATES version.

To measure the performance of the automated ATES algorithm compared to the expertguided NVE maps, we use a simple agreement percentage to assess the algorithm performance. These values are presented in Table 2 and Fig. 5.

\subsection{Algorithm linear route performance}

To assess the performance of the new automated ATES algorithm, we compared the automated ATES data to $586 \mathrm{~km}$ of linear tracks from 123 expert-guided routes classified by NVE in 2019. These linear routes were manual classified and accounted for forest, which the current version of our automated ATES algorithm does not. For this reason, all areas with forest are removed from this analysis, and only "open" terrain is considered. For Romsdalen, this represented approx. $60 \%$ of all classified terrain, whereas for Lofoten and Troms, this represented approx. $80 \%$ of all classified terrain. We used a coarser forest layer (Gjertsen and Nilsen 2012), which only provided binary data of forest or open (and not density and vegetation type, which would be needed for full implementation into ATES), 
Table 3 Percentage agreement score comparing $586 \mathrm{~km}$ of manually classified linear routes and the automated ATES algorithm (if more hazardous than the manual classification, marked in italics)

\begin{tabular}{lccc}
\hline & \multicolumn{2}{c}{ Automated ATES (\%) } \\
\cline { 2 - 3 } & Class 1 & Class 2 & Class 3 \\
\hline NVE expert linear & & & \\
Troms (191 km) & & & \\
Class 1 & 91.67 & 6.29 & 2.04 \\
Class 2 & 61.43 & 35.66 & 2.91 \\
Class 3 & 60.86 & 25.52 & 13.62 \\
Lofoten (113 km) & & & \\
Class 1 & 90.77 & 7.69 & 1.53 \\
Class 2 & 59.53 & 37.44 & 3.03 \\
Class 3 & 44.04 & 42.82 & 13.14 \\
Romsdalen (281 km) & & & \\
Class 1 & 88.30 & 11.23 & 0.47 \\
Class 2 & 52.22 & 41.53 & 6.24 \\
Class 3 & 34.29 & 55.92 & 9.79 \\
Average & & & \\
Class 1 & 90.52 & 8.00 & 1.48 \\
Class 2 & 57.10 & 38.53 & 4.37 \\
Class 3 & 43.14 & 45.43 & 11.43 \\
\hline
\end{tabular}

which permitted removal of these areas from this analysis. To measure the performance of the algorithm compared to the expert-guided NVE maps, the agreement percentage is again used to assess the algorithm performance. These values are presented in Table 3. Given the conservative nature of the manual ATES classification of these routes, we have highlighted (in italics) the \% of terrain that the automatic ATES algorithm categorizes as more hazardous than the manual classification.

\section{Discussion}

\subsection{Comparison to other avalanche mapping work}

Various other automated models have been proposed to create ATES maps. Schmudlach and Köhler (2016) developed an algorithm that computes a 10-m continuous ATES map based on the statistical likelihood of human-triggered avalanches. A drawback with this method is that it is solely based on expert judgement without validation against other referenced ATES mapping (e.g., Statham et al. 2006) or ATES mapping (e.g., Campbell and Gould 2013). Thumlert and Haegeli (2017) developed a mapping algorithm from the movement of professional ski guides. They developed an ATES map with a spatial resolution of $20 \mathrm{~m}$ and showed that it was possible to make an ATES map based on observed terrain use from professional ski guides. However, they acknowledge that the method has several limitations including having to decide whether the skied terrain was a wise decision or not, and therefore to determine whether to include it in the dataset or not. The method is also computationally expensive and only derived from one snow climate over two seasons, making it vulnerable if applied for different climates and wildly different terrain types. In 
an alternative approach to mapping avalanche terrain, Harvey et al. (2018) developed avalanche terrain maps by combining avalanche terrain characteristics similar to our study, but then utilized multiple parameterizations of the RAMMS model to estimate runout distances. This method was used to make nationwide avalanche maps for Switzerland. They concluded that ATES was not appropriate for the European Alps because of too many trips being classified as "complex", and they ending up creating a new classification. The output was both a continuous and discrete map providing information of the consequences of traveling in avalanche terrain. Barbolini et al. (2011) proposed a new methodology to perform avalanche hazard mapping over large areas. This method combine two modules; (1) used to define potential release areas based on slope, morphology and vegetation, and (2) a runout algorithm (AFRA) which provides an automatic definition of areas that could be affected by an avalanche. We believe that our approach, using an automated algorithm makes it possible to map large areas at a low cost using the well-known and pragmatic ATES classification scheme. The algorithm only needs a DTM as input and can be adjusted for different climates using different alpha angles, making it very versatile.

\subsection{Algorithm spatial performance}

To create an automated algorithm for ATES terrain classification, it is challenging to use the qualitative classification (v1.04) proposed by Statham et al. (2006). Therefore, the quantitative model proposed by Campbell and Gould (2013) is used. It is primarily derived from slope incline and land forest density, but the model additionally emphasizes start zone density, interaction with avalanche paths, terrain traps and curvature (Table 1).

When we apply our algorithm to open terrain, we can efficiently map terrain as per the thresholds proposed by Campbell and Gould (2013). In specific, when we compare our algorithm-based ATES map results with the more generalized manual ATES maps as produced by avalanche experts, we see that the algorithm-based maps are explicit in their classification (Fig. 4). Comparing the manual ATES maps with the thresholds from Campbell and Gould (2013), it was found that they were more generous in their classification and added more adjacent terrain to the classification, yielding a smoother, more generic ATES map than the algorithm approach. This first phase of manual ATES mapping was an early pilot project and as we see in Sect. 3.2, the later manual mapping is more consistent with our automated algorithm. Figure 4 shows that the algorithm produces a broadly similar spatial pattern as the NVE classification. Specifically for Fagerfjellet (Fig. 4, (1)), the long narrow corridor in the lower middle is identified in both maps. Some small areas of this corridor are determined as challenging by the algorithm, but these areas are located below the tree line and would possibly be classified down to simple terrain if a forest density mask was included. Above this corridor (Fig. 4, (2)), NVE has classified the area as simple and challenging terrain. The algorithm identified this as a potential start zone, and therefore been classified as complex. Likewise, for Gabrielfjellet (Fig. 4, (3)), the algorithm produces a broadly similar spatial pattern as the NVE classification, with the marked exception of an area of complex terrain in the algorithm-based map, where the manual map has classified this as simple terrain. This difference can likely be attributed to a section of cliffs that was overlooked in the pilot manual mapping project, while the algorithm identified this feature, leading to a higher class. Finally, for Skittentinden (Fig. 4, (4)), the algorithm produces a broadly similar spatial pattern as the NVE classification but with more nuanced spatial patterns differentiating challenging from complex terrain in the upper half of the mapped area. However, this increased spatial resolution expressed in this 
nuanced pattern is likely not helpful for the user because these pockets of challenging terrain are not useable without prior exposure to adjacent complex terrain. As evidenced by these three case study examples, and checked in multiple other areas throughout Norway, the algorithm works well for open terrain. However, with the limitation of not explicitly accounting for forest density, which the expert-guided maps do, there is an expected difference in the classification matrix for areas with mixed and forest terrain. Fortunately, for many areas in Norway most recreational ski touring occurs well above the treeline (e.g., in Troms and Romsdalen approximately $60-80 \%$ of the distance of the individual mapped tours are above the treeline). However, due to these limitations, the algorithm maps should not be compared directly with the manual ATES maps, but rather compared more broadly to assess if the resulting patterns are consistent with the manual expert mapping. Using this approach, it is clear that the algorithm is producing similar ATES results as the manual method, but with more nuanced details for terrain classifications. Furthermore, the ATES results are conservative results due to the exclusion of forest cover parameters.

\subsection{Algorithm linear route performance}

Directly comparing the algorithm-based ATES map and the manually categorized ATES linear routes is also complicated and with only moderate explanatory power. We do not expect an ATES linear route of "simple" to be $100 \%$ simple, but we do expect the vast majority of it to be in simple terrain. As we see in our results (Table 3), the values for agreement between the algorithm-based ATES map and the linear route for simple terrain range from 88 to $92 \%$, suggesting that the vast majority of the route is within the simple class. However, one-tenth of a simple route is within challenging or complex terrain, suggesting either that our classification of simple terrain is either to conservative, or the experts from NVE are too generous in their classification.

Likewise, we assume that for "challenging" linear routes, that the majority of the route is in simple to challenging terrain, whereas very little should be in complex terrain. In our results, we get values of between 2 and 6\% in complex terrain, suggesting that 94-98\% of challenging routes are within terrain that the algorithm classifies as simple to challenging terrain. For "complex" terrain, we are unable to repeat this analysis because only a small fraction of a route can result in a manual classification of complex (e.g., 10\% for Romsdalen region), even though most of the route is in simple or challenging terrain.

For validation of challenging terrain, we rely on the spatial comparison in Sect. 3.2, manual spot checks of areas clearly representing challenging terrain, and with knowledge that the algorithm performs within the thresholds proposed by Campbell and Gould (2013). In general, the linear tracks show broadly consistent results across all three regions and classes, suggesting that the experts from NVE do not display any regional bias in their classification of manual ATES routes. Furthermore, we see that the percentage agreements are very high for simple and challenging terrain, which is encouraging for the algorithmbased ATES maps. The challenge with this analysis is that we are unable to assess which of the methods, if any, is $100 \%$ accurate, so a direct comparison and direct interpretation of these results are problematic. Despite this, we see that the algorithm is producing ATES maps that compare very favorably, and in some cases produce more realistic maps than the manual ATES mapping approaches for both spatial- and route-based applications. 


\subsection{Limitations}

While we are encouraged by the results of this algorithm, urge caution in their use due to a number of limitations. Slope angle is identified as the most important factor for ATES delineation. Using the thresholds proposed from Campbell and Gould (2013), it was possible to divide the terrain into rough classes early in the processing. It was found that when using the non-avalanche threshold of $20^{\circ}$, simple terrain was neglected, to avoid this, the threshold was lowered to $15^{\circ}$ in the automated ATES algorithm. However, the consequences of mapping thousands of square kilometers as non-avalanche terrain with only minimal case study validation, and high public use, could lead to dangerous scenarios. Therefore, it was decided to remove the non-avalanche terrain entirely from the publicly available maps until a robust vegetation layer is available, and appropriate safety margins can be applied. A nationwide highresolution DTM from aerial light detection and ranging (LIDAR) will be available in 2022 (Kartverket 2019), which will permit high-resolution assessment terrain, and greatly improve the current algorithm.

The second most important factor in the method is the forest density parametrization. Implementing this into the algorithm should be uncomplicated based on the published thresholds dividing the density into open, mixed and forest (Table 1). At this stage, however, it has not been implemented in the current algorithm due to the lack of reliable forest density data for Norway at the relevant spatial scale. Options such as the area resource map (AR5) have been considered, but the accuracy of the data is limited (Gjertsen and Nilsen 2012). Norwegian Institute of Bioeconomy Research (NIBIO) is working on a high-resolution forest resources' map (SR16) which is produced by automatic modeling of AR5, DTM, aerial LIDAR and photogrammetry data (NIBIO 2019). When this dataset becomes available nationwide, it could be implemented in the algorithm to account for the effect of forest on avalanches. Quantifying the effect of forest density for each region, we found that in Romsdalen, approximately $40 \%$ of the length of the mapped manual routes are within areas with mixed forest or forest, as compared to Lofoten and Troms where forest only covered approx. 20\% of the total route length. Thus, it is more likely that the automated algorithm is correct at higher latitudes where the forest is less extensive, and the vegetation elevation is lower. Routes with a large percentage of forested terrain would however receive a conservative classification due to the exclusion of the forest parameter.

To account for start zones, the PRA script developed by Veitinger et al. (2016) is used. To calculate the release areas, the script uses the three parameters: slope, wind shelter index and roughness. This script was optimized for a 2-m DTM, but both a finer and coarser scale DTM could be applied (Veitinger et al. 2016). Currently, a 10-m DTM is the best available resolution for mainland Norway and is therefore used. In practice, the roughness parameter is currently being neglected due to the coarse scale of the DTM. The automated ATES algorithm has also been successfully applied at Nordenskiöld Land at a 5-m DTM resolution without doing any changes to the script. To account for downslope and cross-slope curvature, the wind shelter index is used. Numerous studies show that wind shelter index from a DTM can accurately reflect the accumulated snow patterns (e.g., Schirmer et al. 2011; Winstral et al. 2002). Despite these limitations, this automated algorithm and the workflow presented provide a tangible first step forward toward fully automated and consistent and reproducible ATES mapping. Future advancements will refine and improve this algorithm over time. 


\section{Conclusion}

This paper presents a fully automated algorithm that is able to produce a high-resolution nationwide ATES map for Norway from a DTM. Validating the new ATES maps with regions that had expert-guided ATES maps and linear routes as produced by NVE showed high consistency in all regions, when only open terrain was considered. For forested areas, which comprise the minority of avalanche terrain assessed, we get mixed results. Thus, future work should focus on incorporating vegetation data at the appropriate spatial resolution when it becomes available to further improve the automated ATES algorithm. However, a large percentage of the Norwegian backcountry terrain is above the tree line (approx. $80 \%$ for Troms and $60 \%$ for Romsdalen), thus the current algorithm is already a helpful tool for expert-guided mapping and as recreational trip planning tool. The automated algorithm is also useful to increase the consistency between different experts mapping ATES manually in different regions of Norway. Finally, another advantage of using an automated approach, in contrast to expert-based methods, is the reproducibility of the mapping and future updates and improvements can easily be performed.

Acknowledgements The authors would like to thank the two anonymous reviewers for the thorough and constructive reviews. We also acknowledge the support from NVE to complete this project.

Authors' contributions Conceptualization: Håvard Toft Larsen, Jordy Hendrikx; Methodology: Håvard Toft Larsen, Jordy Hendrikx; Formal analysis and investigation: Håvard Toft Larsen, Jordy Hendrikx; Writingoriginal draft preparation: Håvard Toft Larsen, Jordy Hendrikx; Writing_review and editing: Håvard Toft Larsen, Jordy Hendrikx, Martine Sagen Slåtten, Rune Verpe Engeset; Resources: Håvard Toft Larsen, Jordy Hendrikx, Martine Sagen Slåtten, Rune Verpe Engeset; Supervision: Jordy Hendrikx, Martine Sagen Slåtten, Rune Verpe Engeset.

Open Access This article is licensed under a Creative Commons Attribution 4.0 International License, which permits use, sharing, adaptation, distribution and reproduction in any medium or format, as long as you give appropriate credit to the original author(s) and the source, provide a link to the Creative Commons licence, and indicate if changes were made. The images or other third party material in this article are included in the article's Creative Commons licence, unless indicated otherwise in a credit line to the material. If material is not included in the article's Creative Commons licence and your intended use is not permitted by statutory regulation or exceeds the permitted use, you will need to obtain permission directly from the copyright holder. To view a copy of this licence, visit http://creativecommons.org/licenses/by/4.0/.

\section{References}

Arnalds P, Jónasson K, Sigurdsson S (2004) Avalanche hazard zoning in Iceland based on individual risk. Ann Glaciol 38:285-290. https://doi.org/10.3189/172756404781814816

Barbolini M, Pagliardi M, Ferro F, Corradeghini P (2011) Avalanche hazard mapping over large undocumented areas. Nat Hazards 56:451-464. https://doi.org/10.1007/s11069-009-9434-8

Birkeland KW, Greene EM, Logan S et al (2017) In response to avalanche fatalities in the United States by Jekich et al. Wilderness Environ Med 28:380-382. https://doi.org/10.1016/j.wem.2017.06.009

Bodansky E, Gribov A, Pilouk M (2002) Smoothing and compression of lines obtained by raster-to-vector conversion. In: Blostein D, Kwon Y-B (eds) Graphics recognition algorithms and applications. Springer, Berlin, pp 256-265

Brenning A (2008) Statistical geocomputing combining R and SAGA: the example of landslide susceptibility analysis with generalized additive models. Hamburg Beiträge zur Phys Geogr und Landschaftsökologie 19:23-32

Bühler Y, Von Rickenbach D, Stoffel A et al (2018) Automated snow avalanche release area delineationvalidation of existing algorithms and proposition of a new object-based approach for large-scale 
hazard indication mapping. Nat Hazards Earth Syst Sci 18:3235-3251. https://doi.org/10.5194/nhess $-18-3235-2018$

Campbell C, Gould B (2013) A proposed practical model for zoning with the Avalanche Terrain Exposure Scale. In: International Snow Science Workshop Proceedings, Grenoble-Chamonix Mont-Blanc. pp 385-391

Campbell C, Gould B, Newby J (2012) Zoning with the Avalanche Terrain Exposure Scale. International snow science workshop proceedings. Anchorage, Alaska, pp 450-457

Canadian Avalanche Association (2002) Guidelines for snow avalanche risk determination and mapping in Canada

Canadian Avalanche Association (2016) Technical aspects of snow Avalanche risk management-resources and guidelines for Avalanche practitioners in Canada. Canadian Avalanche Association, Revelstoke, British Columbia

Conrad O, Bechtel B, Bock M et al (2015) System for automated geoscientific analyses (SAGA) v. 2.1.4. Geosci Model Dev 8:1991-2007. https://doi.org/10.5194/gmd-8-1991-2015

Delparte DM (2008) Avalanche terrain modeling in Glacier National Park, Canada. PhD thesis 1-195. https ://doi.org/10.1007/s13398-014-0173-7.2

Engeset RV (2013) National Avalanche Warning Service for Norway-established 2013. In: International Snow Science Workshop Proceedings, Grenoble-Chamonix Mont-Blanc. pp 301-310

Engeset RV, Pfuhl G, Landrø M et al (2018) Communicating public avalanche warnings-what works? Nat Hazards Earth Syst Sci 18:2537-2559. https://doi.org/10.5194/nhess-18-2537-2018

Gavaldà J, Moner I, Bacardit M (2013) Integrating the ATES into the Avalanche Information in Aran Valley (Central Pyrenees). In: International Snow Science Workshop Proceedings, Grenoble - Chamonix Mont-Blanc. pp 381-384

Gjertsen AK, Nilsen J (2012) SAT-SKOG - Et skogkart basert på tolkning av satelittbilder. Nor Inst Skog og Landsk 1-16

Gruber U, Bartelt P (2007) Snow avalanche hazard modelling of large areas using shallow water numerical methods and GIS. Environ Model Softw 22:1472-1481. https://doi.org/10.1016/j.envso ft.2007.01.001

Haegeli P, Mccammon I, Jamieson JB, et al (2006) The Avaluator - A Canadian Rule-based Avalanche Decision Support Tool For Amateur Recreationists. In: International Snow Science Workshop, Telluride, pp 254-263

Harvey S, Schmudlach G, Bühler Y, et al (2018) Avalanche Terrain Maps For Backcountry Skiing in Switzerland. In: International Snow Science Workshop Proceedings, Innsbruck, Austria. pp 1625-1631

Kartverket (2013) Digital Elevation Model 10 m. In: Nor. Mapp. Auth. https://kartkatalog.geonorge.no/ metadata/kartverket/dtm-10-terrengmodell-utm33/dddbb667-1303-4ac5-8640-7ec04c0e3918

Kartverket (2019) Nasjonal detaljert høydemodell. In: Nor. Mapp. Auth. https://kartverket.no/hoyde modell. Accessed 27 Jun 2019

Landrø M, Engeset R, Haslestad A, et al (2016) The Norwegian Avalanche Observer Corps: Safety, Quality, Training, Procedures and Culture. In: International Snow Science Workshop Proceedings, Breckenridge, Colorado. pp 922-928

Landrø M, Hetland A, Engeset RV, Pfuhl G (2020) Avalanche decision-making frameworks: factors and methods used by experts. Cold Reg Sci Technol. https://doi.org/10.1016/j.coldregions.2019.102897

Larsen HT (2019a) ATES Automated Model Script https:/github.com/hvtola/Autokast/blob/master/ AutokastBatch.py

Larsen HT (2019b) ATES Automated Generalization Script https://github.com/hvtola/Autokast/blob/ master/Generalization.py

Lied K, Bakkehøi S (1980) Empirical calculations of snow avalanche run-out distances based on topographic parameters. J Glaciol 26:165-177

NGI (2019) Ulykker med død. In: Nor. Geotech. Inst. https://www.ngi.no/Tjenester/Fagekspertise/Snoes kred/snoskred.no2/Ulykker-med-doed. Accessed 20 Sep 2019

NIBIO (2019) Skogressurskart (SR16). In: Nor. Inst. Bioeconomy Res. Webpage. https://www.nibio.no/ tema/skog/kart-over-skogressurser/skogressurskart-sr16. Accessed 27 Jun 2019

NPRA (2019) The National Road Database. In: Nor. Public Roads Adm. https://www.vegvesen.no/vegka rt/vegkart. Accessed 28 Jun 2019

NVE (2014) FoU-prosjekt 81072 Pilotstudie: Snøskredfarekartlegging med ATES (Avalanche Terrain Exposure Scale). The Norwegian Water Resources and Energy Directorate

Sauermoser S (2006) Avalanche hazard mapping-30 Years experience in Austria. In: International Snow Science Workshop Proceedings, Telluride, pp 314-321 
Schirmer M, Wirz V, Clifton A, Lehning M (2011) Persistence in intra-annual snow depth distribution: 1. Measurements and topographic control. Water Resour Res 47:1-16. https://doi.org/10.1029/2010W R009426

Schmudlach G, Köhler J (2016) Method for an automatized avalanche terrain classification. In: Proceedings, International Snow Science Workshop, Breckenridge, pp 729-736

Schweizer J (2003) Snow avalanche formation. Rev Geophys 41:1016. https://doi.org/10.1029/2002R G000123

Statham G, McMahon B, Tomm I (2006) The avalanche terrain exposure scale. Int Snow Sci Work Proceedings, Telluride, 491-497

Tarboton DG (2005) Terrain analysis using digital elevation models (TauDEM)

Tarboton DG (2013) TauDEM 5.1-Guide to using the TauDEM command line functions

R Core Team (2017) A language and environment for statistical computing

Techel F, Mitterer C, Ceaglio E et al (2018) Spatial consistency and bias in avalanche forecasts-a case study in the European Alps. Nat Hazards Earth Syst Sci 18:2697-2716. https://doi.org/10.5194/ nhess-18-2697-2018

Thumlert S, Haegeli P (2017) Describing the severity of avalanche terrain numerically using the observed terrain selection practices of professional guides. Nat Hazards. https://doi.org/10.1007/ s11069-017-3113-y

Varsom (2019a) Snøskredulykker- og hendelser. In: Nor. Avalanche Warn. Serv. Website. https://www.varso m.no/ulykker/snoskredulykker-og-hendelser/. Accessed 20 Sep 2019

Varsom (2019b) KAST Teknisk Modell. In: Nor. Avalanche Warn. Serv. Website. https://www.varsom.no/ snoskredskolen/skredterreng/kast-klassifisering-av-snoskredterreng/kast-teknisk-modell/?ref=mainm enu. Accessed 17 Sep 2019

Varsom (2019c) KAST - Klassifisering av snøskredterreng. In: Nor. Avalanche Warn. Serv. Website. https:// www.varsom.no/snoskredskolen/skredterreng/kast-klassifisering-av-snoskredterreng. Accessed 28 Jun 2019

Veitinger, J., Sovilla, B., and Purves RS (2016a) Model code of release area algorithm. https://github.com/ jocha81/Avalanche-release. Accessed 4 Jan 2018

Veitinger J, Sovilla B (2016b) Linking snow depth to avalanche release area size: measurements from the Vallée de la Sionne field site. Nat Hazards Earth Syst Sci 16:1953-1965. https://doi.org/10.5194/nhess -16-1953-2016

Veitinger J, Purves SR, Sovilla B (2016) Potential slab avalanche release area identification from estimated winter terrain: a multi-scale, fuzzy logic approach. Nat Hazards Earth Syst Sci 16:2211-2225. https:// doi.org/10.5194/nhess-16-2211-2016

Winstral A, Elder K, Davis RE (2002) Spatial snow modeling of wind-redistributed snow using terrainbased parameters. J Hydrometeorol 3:524-538. https://doi.org/10.1175/1525-7541(2002)003\%3c052 4:SSMOWR\%3e2.0.CO;2

Publisher's Note Springer Nature remains neutral with regard to jurisdictional claims in published maps and institutional affiliations. 